\title{
Effect of salicylic acid on protease and urease activity in soils under Norway spruce pure stands
}

\author{
Ladislav Holik*, Aleš Kučera, Klement Rejšek, Jana Rosíková, Valerie Vranová
}

Mendel University in Brno, Faculty of Forestry and Wood Technology, Department of Geology and Soil Science, Zemědèlská 3, 61300, Brno, Czech Republic.

*Corresponding author: Ladislav Holik, email: ladislav.holik@mendelu.cz

\begin{abstract}
This study tested the hypothesis that soil protease and urease activity is inhibited by salicylic acid. This was tested in soils from spruce monocultures of different ages and treated by different forest management methods at the Rájec-Němčice Ecosystem Station. Surface organic H-horizons from three study plots were sampled: a mature spruce monoculture of 105 years and two young spruce monocultures of 33 years, one of which was thinned from above and the other thinned from below. Statistically significant differences between the measured values confirm that young stands are sensitive to the presence of 2-hydroxybenzoic acid as a phytotoxic substance. The results of this study do not conclusively show whether the effect of salicylic acid on protease activity inhibition increases when the protease activity itself is high. The impact of salicylic acid on soil urease activity was not clearly evident either.
\end{abstract}

Keywords: Soil enzymes, salicylic acid, spruce forest, ammonium nitrogen

\section{Introduction}

Coniferous litter is the main raw material in the production of humus in organic horizons of spruce forest ecosystems, and represents one of the main substrates for microbial degradation (Enowashu et al., 2009). Microorganisms are responsible for the conversion of dead organic matter into bioavailable nitrogen forms.
Soil is continuously being enriched with organic compounds such as exudates from living plants, dead cells of microorganism and dead bodies of plants and animals (Błońska and Lasota, 2014). The rhizosphere is often described as an area of soil surrounding the plant roots, which is directly influenced by plant roots and associated biota. This area is filled 
with microorganisms that feed on the compounds released from plant roots and can increase the nutrient uptake by plant roots, while allowing nutrition from otherwise inaccessible sources of nutrients in the soil (Moe, 2013). Microorganisms, including soil mycorrhiza, secrete proteases into the soil to facilitate the decomposition of proteins and peptides into amino acids (Kandeler et al., 1999). There are a large number of proteins and peptides in the soil, with proteases providing a large portion of biologically available nitrogen (Geisseler and Horwath, 2008; Vranova et al., 2013). Another important enzyme in the nitrogen cycle is urease. Soil urease is involved in the mineralization of organic matter through the hydrolysis of urea and amine to ammonium ion $\mathrm{NH}_{4}^{+}$ (Ojeda-barrios et al., 2016). The enzyme activity is influenced by various physical and biochemical factors such as plant litter quantity or quality, as well as the quality of exudated substances, depending on the plant species. Moreover, enzyme activity may be affected by physical factors including soil temperature, soil moisture content and distribution and the soil pH (Tharayil et al., 2013; Aragón et al., 2014).

One of the substances that affect the activity of plants and microorganisms is salicylic acid (2-hydroxybenzoic acid), which belongs to a diverse group of plant phenolic compounds. These substances play a crucial role in the regulation of physiological processes in plants, such as plant growth and development (Dong et al., 2015), photosynthesis and flowering. These substances also affect root growth and are essential for plant germination (Popova et al., 1997). Within the rhizosphere, salicylic acid is produced by some genera of bacteria such as Azospirillum, Pseudomonas, Mycobacterium and Yersinia (Mauch et al., 2001). Salicylic acid that is produced in the rhizosphere from root exudates or synthesized by microbes may play a role in allelopathy and inhibit the growth of neighboring plants (Schettel and Balke, 1983).

This study evaluates the seasonal dynamics of soil protease and urease in the organic horizon beneath stands of spruce (Picea abies /L./ Karst, Pinaceae) and their response to addition of salicylic acid.

\section{Materials and Methods}

\subsection{Study plots and soil sampling}

The research was carried out at the Rájec-Němčice Ecosystem Station in the Drahanská vrchovina Highlands (the Czech Republic), located at $49^{\circ} 29^{\circ}$ $\mathrm{N}$ and $16^{\circ} 43^{\prime} \mathrm{E}$ at an altitude of $600-660 \mathrm{~m}$ a.s.1. The geological subsoil is acid granodiorite and the soil type is Dystric Cambisol (IUSS Working Group WRB 2006). The mean annual air temperature is 6.5 ${ }^{\circ} \mathrm{C}$ and annual precipitation is $717 \mathrm{~mm}$. Three study plots with differently managed stands (treatments) were chosen: i) a mature spruce stand (MSS), 105 years, monoculture; ii) a young spruce stand thinned from above (STFA), 33 years, monoculture; iii) a young spruce stand thinned from below (STFB), 33 years, monoculture. In the two young stands, seedlings were originally planted with the spacing 2.5 $\times 2 \mathrm{~m}$ on a clearing after the felling of a mature spruce stand. Thinning operations by two different silvicultural practices were performed in 1986, 2002 and 2010.

Surface organic $\mathrm{H}$ horizons were sampled (IUSS Working Group WRB 2006) monthly throughout the year 2014. To achieve the highest representativeness and to avoid pseudo-replication, we sampled the soil at each of the three study plots, where six mixed soil samples were composed of three sub-samples collected each month by the same method. In the laboratory, the naturally moist samples were sieved through a 4 mm sieve, mixed and stored at $5{ }^{\circ} \mathrm{C}$ until use. 


\subsection{Soil and statistical analysis}

Determination of the potential protease activity was carried out according to Ladd and Butler (1972) where hydrolysis of casein was followed by the production of L-tyrosine. Determination of the potential urease activity was based on the method by Kandeler and Gerber (1988) aimed at the determination of the ammonium released from the soil samples after incubation with urea. Ammonia nitrogen in soils was measured by the methodology published by Kucera et al. (2013). Salicylic acid was added to the sample before incubation in the amount of $2 \mathrm{mg}$ per gram of dry soil. Incubation was short ( 2 hours) and proceeded in concert with incubation to determine the activity of soil proteases or ureases.

Statistical analysis performed by ANOVA was based on the null hypothesis (H0), verified through p-value (indicated as „Pr $(>\mathrm{F}) “$ ); in multiple comparisons, it was based on the post-hoc analysis by the Tukey HSD test where the null hypothesis is verified through pvalue (indicated as "p adj"). A two-way ANOVA was therefore performed, and month and silvicultural practice (SilvPra) were tested at the significance level alpha $=0.05$ (conf. interval $=0.95)$.

Principal component analysis (PCA) was used to determine the variance of linear combinations of vectors coming from the selected variables and to detect any multidimensional relationships between the variables. The confidence ellipses were computed on the confidence level of 0.95 . The statistical analysis was performed in the R environment using the prcomp from factoextra package, version 1.0.4 (Kassambara and Mundt, 2017).

\section{Results}

The results of statistical analyses allowed us to make conclusions regarding the mutual relationships be- tween the proteases and their substrate, ureases and their substrate and response of both enzymes to the addition of the phytotoxic substance, salicylic acid. Regarding the seasonal dynamics of protease activity (Figure 2), individual months were markedly different, i.e., a statistically significant character of the development of the activity of the enzymes involved in their decomposition in time was confirmed. The phytotoxic effect of the salicylic acid (Figure 3) was significantly linked to the dynamics of the different seasons, with the effect being lowest in September and highest in June. The significantly highest protease activity was found in June - the lowest in STFB and the highest in STFA; however, after the addition of salicylic acid, the protease activity was lowest in STFB again, but the highest appeared in MSS. This means that in the young forest stands, the salicylic acid limited protease activity, which contrasts with the old-aged forest, where, after the addition of salicylic acid, protease activity increased. The differences in protease activity between the individual differently managed stands were indistinct. On the contrary, the addition of the phytotoxic substance had a larger and more ambivalent impact on proteases in both young stands; the highest effect of salicylic acid was observed in the young stand thinned from below (Figure 3). The phytotoxic effect of salicylic acid on proteases in the mature stand was much lower than in the young stands. Furthermore, in MSS, protease activity each month was more or less higher after the addition of salicylic acid.

The highest concentrations of ammonium nitrogen in H-horizons of the three investigated spruce stands were found in May (Figure 1), especially in MSS; in June they were very low. With regards to the presence of ammonium nitrogen in H-horizons of the three spruce stands studied (Figure 5), the highest concentration was in the MSS in May; similarly, urease activity was the lowest here as was its reaction to the addition of salicylic acid (Figure 5). The activity of 
urease also showed statistically significant seasonal dynamics (Figure 4); significant differences were confirmed in both grouping variables (months, SilvPra). The lowest urease activity was found in the MSS, followed by the STFA and STFB (slightly higher). In each of the forest management practices, the seasonal dynamics were markedly different with maximums in

(a)

$95 \%$ family-wise confidence level
July and in STFB a maximum in October (Figure 4). The controlled addition of salicylic acid did not lead to a decrease in urease activity; the highest activity of this enzyme was observed again in July. The differences between the forest management practices were similar to those observed in the samples without the salicylic acid, but with fewer significant differences (Figure 5). (b)

$95 \%$ family-wise confidence level

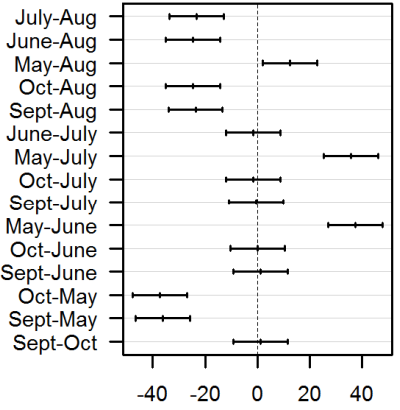

Differences in mean levels of MONTH

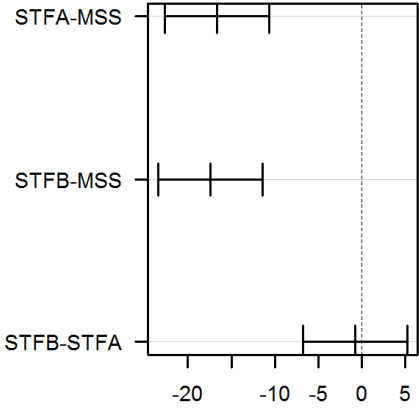

Differences in mean levels of SilvPra

Figure 1. Statistical evaluation of the amount of ammonia nitrogen in the H-horizon of the mature spruce stand and the two young spruce stands. Use of a two-way ANOVA, alpha $=0.05$, grouping variable (a) months, and (b) SilvPra

(a)

$95 \%$ family-wise confidence level (b)

\section{$95 \%$ family-wise confidence level}

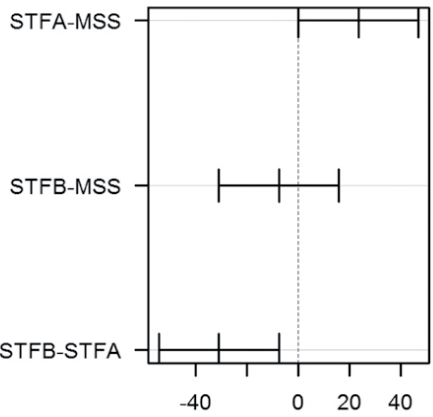

Differences in mean levels of SilvPra

Figure 2. Statistical evaluation of soil protease activity in H-horizon of the mature spruce stand and the two young spruce stands. Use of a two-way ANOVA, alpha $=0.05$, grouping variable (a) months, and (b) SilvPra. 
(a)

$95 \%$ family-wise confidence level (b)

\section{$95 \%$ family-wise confidence level}

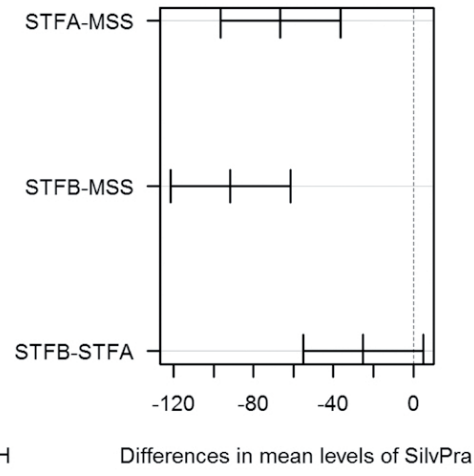

Differences in mean levels of SilvPra

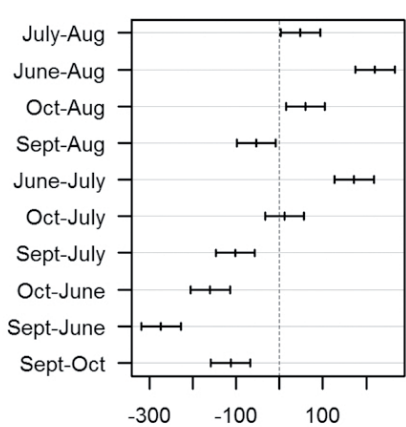

Differences in mean levels of MONTH

.

Figure 3. Statistical evaluation of protease activity of the soil with addition of salicylic acid in H-horizon of the mature spruce stand and the two young spruce stands. Use of a two-way ANOVA, alpha $=0.05$, grouping variable (a) months, and (b) SilvPra.

(a)

$95 \%$ family-wise confidence level (b)

\section{$95 \%$ family-wise confidence level}

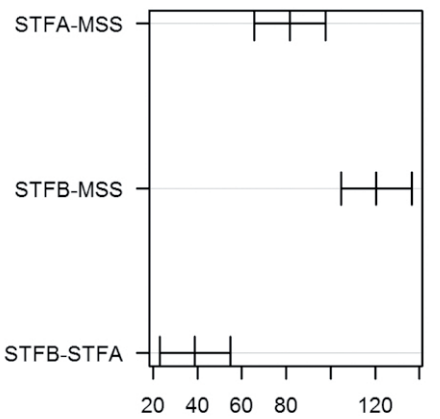

Differences in mean levels of SilvPra

Figure 4. Statistical evaluation of the activity of soil urease in H-horizon of the mature spruce stand and the two young spruce stands. Use of a two-way ANOVA, alpha $=0.05$, grouping variable (a) months, and (b) SilvPra. 
(a)

$95 \%$ family-wise confidence level (b)

$95 \%$ family-wise confidence level

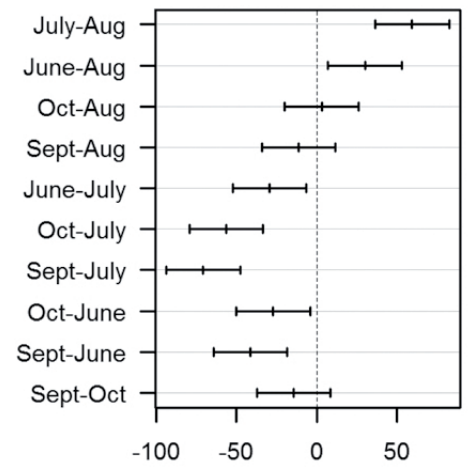

Differences in mean levels of MONTH

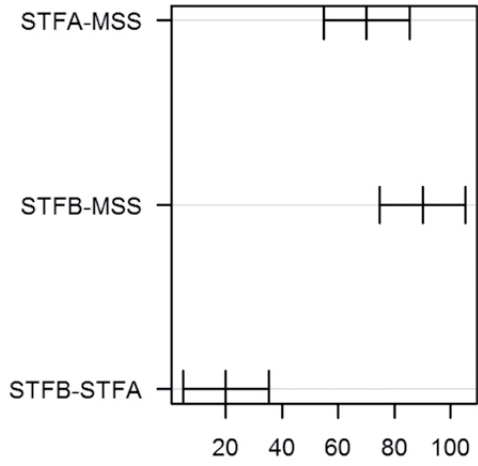

Differences in mean levels of SilvPra

Figure 5. Statistical evaluation of the activity of soil urease after addition of salicylic acid in the H-horizon of the mature spruce stand and the two young spruce stands. Use of a two-way ANOVA, alpha $=0.05$, grouping variable (a) months, and (b) SilvPra.

The scores plot (Figure 6) shows the relationships between the individual variables SilvPra in the terms of dimension 1 (x-axis) and dimension 2 (y-axis) of the PCA analysis. The silvicultural practice-based close data are marked by confidence ellipses enclosing data coming from MSS (left ellipse), STFA (central ellipse) or STFB (right ellipse). Themonth-based close data are shown in Figure7. The individual results of each silvicultural treatment in each month are well clustered in the factor map, which shows the welldetermined site-specific and seasonal-specific features of the treatments. The STFA SilvPra is close to the center and therefore more representative compared to the other treatments. However, the individuals are also typical when considering the MONTH variable. The cloud of points in the upper part of the factor map comes from the treatment MSS sampled in June, where the values of Protease+Salicylic Acid were markedly higher; hence, the values of the individual results are influenced by this factor. In Figure 7, months that are rather symmetrically distributed near the beginning of the factor map (October, May and July) show similar values, while June is typical with higher values of variables in both dimensions, and August and September are typical with lower values of the variables, especially on the $\mathrm{x}$-axis. The tested variables show good representativeness for the SilvPra and MONTHS. The variables are grouped in two couples in a factor map (Figure 6; Figure 7): protease activity, both with or without the addition of salicylic acid correlated well with the second principal component while urease activity correlated with the first principal component. Both types of enzymatic activities were strongly correlated after the addition of salicylic acid. The ammonium ion $\left(\mathrm{NH}_{4}^{+}\right)$concentration was detected as a variable of strong negative correlation with the first principal component; furthermore, a negative correlation with urease activity and independency on protease activity was detected. However, Figures 6 and 7 show that the variables are well separated into 
groups according to (1) enzymatic activity producing different forms of nitrogen, typical with positive correlation with first two components and (2) product of the enzymatic activity (ammonium ion) following the principal component 1 with negative correlation. The first two components predict ca $83 \%$ of the variability (see also Table 1) with two separated logical groups.

Based on the results, the treatments were found to be seasonally and forest-management type specific with regards to the amount of ammonium nitrogen and the activity of protease and urease, both with or without the influence of salicylic acid. The enzymatic activity differed with forest-management type in individual months: protease had its maximum in June and its minimum in September but with low significance of management type, while urease activity was found to be less variable during seasons, with a slight decrease towards autumn, but with significant differences associated with forest management (the most active in STFB, the least active in MSS). However, the inhibition of urease activity was not confirmed to be significant.

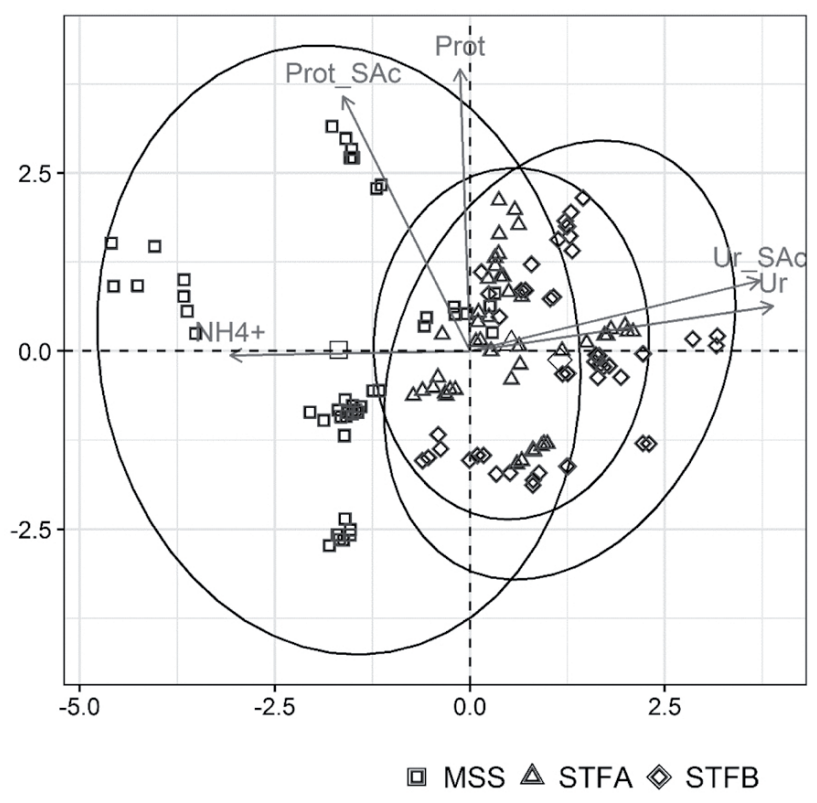

Figure 6. Graphical results (factor map) of PCA for the individuals and variables. $\mathrm{x}$-axis is principal component 1 (Dim 1), y-axis is principal component 2 (Dim 2). The individuals are grouped using all the tested factors, grouped by SilvPra (marked by confidence ellipses). Prot and Ur are proteolytic and ureolytic activity, respectively; Prot_ SAc and Ur_SAc are proteolytic and ureolytic activity of soil, respectively, after addition of salicylic acid and $\mathrm{NH}_{4}+$ is ammonia nitrogen content. 
Table 1. Parameters of the three first principal components of PCA. The variability is well-explained with the percentage of approx. $95 \%$.

\begin{tabular}{lccc}
\hline PCA eigen values & PC 1 & PC 2 & PC 3 \\
\hline Variance & 1.550 & 1.324 & 0.764 \\
Percentage of variance & 0.481 & 0.350 & 0.117 \\
Cumulative percentage of variance & 0.481 & 0.831 & 0.948 \\
\hline
\end{tabular}

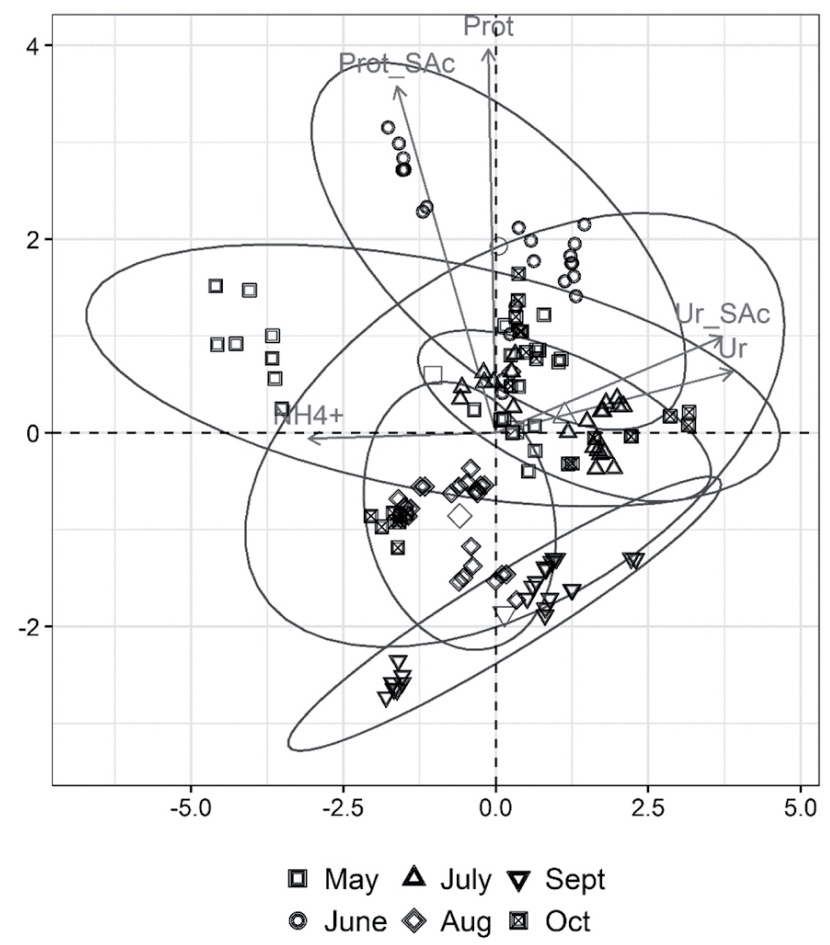

Figure 7. Graphical results (factor map) of PCA for the individuals and variables. $\mathrm{x}$-axis is principal component 1 (Dim 1), y-axis is principal component 2 (Dim 2). The individuals are grouped using all the tested factors, grouped by MONTH (marked by confidence ellipses). Prot and Ur are proteolytic and ureolytic activity, respectively; Prot_SAc and Ur_SAc are proteolytic and ureolytic activity of soil, respectively, after addition of salicylic acid and $\mathrm{NH}_{4}+$ is ammonia nitrogen content. For the supplementary numerical resuts of the PCA see also Table 1. 


\section{Discussion}

In our study, we evaluated the seasonal dynamics of soil protease and urease in combination with an assessment of the total amount of ammonium ions in organic horizons under stands of Norway spruce (Picea abies Karst /L./, Pinaceae). We monitored the dynamics of soil enzymes after the addition of salicylic acid and examined its influence throughout the growing season.

Seasonal cycles of plants - and microorganisms - in forests are closely linked to the availability of nutrients (Bardgett et al., 2005; Harrison et al., 2008; Kaiser et al., 2010). Through their root exudates and quality of litter, plants affect the availability of carbon and nitrogen. During the seasons, plant-soil interactions may be influenced by abiotic factors such as temperature changes and the occurrence of droughts. We also found that there were two peaks of proteases in the months of May and June and a fall peak in September. During the summer, soil proteases activity declined. We can assume that this enzyme is not affected by the type of vegetation or habitat. This is in accordance with the work of Vranova et al. (2009), which dealt with the seasonal effect of protease on meadow habitats and described a gradual decrease in activity during the summer and an early onset of the second peak in September. This differs from our results that showed a peak in October. The course of protease activity may coincide with temperatures and rainfall during the course of the growing season. The activity of the enzyme indicates moister parts of the growing season (spring and autumn) and a drier period during the summer. Weintrub et al. (2005) also point to a possible connection between the availability of and demand for nitrogen by plants and microorganisms. The second peak after a decrease in protease activity comes with improved rainfall conditions and limited availability of nitrogen, which then has a stimulating effect on the microbes that increase its production (Weintraub et al., 2005).

Urease activity at the beginning of the growing season reacts in opposition to the measured quantity of ammonium nitrogen; it rises in June when the amount of ammonia nitrogen decreases (even larger contrast in May). Urease is closely associated with the nutritional conditions at specific locality (Dilly and Nannipieri, 2001). One of the key factors that influence protease is the availability of ammonia nitrogen. The production of urease by microorganisms is negatively regulated by the availability of ammonia nitrogen (Vetanovetz and Peterson, 1992), as was confirmed by our measurements. The amounts of ammonium nitrogen and urease measured at the end of the growing season were balanced. Kang et al. (2009) reported that a decreased amount of ammonium nitrogen is linked with the consumption of microorganisms by the plants for their growth. They also found a significant negative correlation between urease and the concentration of ammonia nitrogen, which agrees with our results.

Our expectation was that the addition of salicylic acid would have a generally inhibitory effect on the enzymatic activity in the soil. Only the protease activity showed inhibition and the urease activity remain unchanged. The month of June showed the lowest inhibitory effect. Salicylic acid belongs to the group of phenolic compounds with different physiological effects (Popova et al., 1997). In compliance with Lyu et al. (1990), Booker et al. (1992), Bergmark et al. (1992) and Amy et al. (2004), we confirmed that phenolic substances often have an allelopathic effect, which is manifested in reduced growth ability or the impaired nutrition of plants and microorganisms.

The amount of salicylic acid in forest soils during the year varies. Muscolo and Sidari (2006) found that the greatest amount of salicylic acid in forest soil is in autumn, and then gradually decreases in winter, with the smallest amount occurring in summer. Based on 
this study, we can conclude that with increasing activity of soil proteases, the amount of salicylic acid in forest soils decreases. Thus, it is possible that salicylic acid is indeed involved in the dynamics of the activity of soil proteases in spruce stands.

\section{Conclusions}

This study presents the seasonal dynamics of soil protease and urease in spruce stands of different ages and the effects of salicylic acid on these enzymes. We also measured the amounts of ammonia nitrogen. The results showed a significant effect of seasonality on the proteolytic activity, with peak activity in spring and autumn and depression in summer, and with a very slight effect on urease, which reflects interdependence with the amount of ammonia nitrogen in the organic horizons of spruce forests. Soil protease activity was affected by salicylic acid, but the effect was not proved for soil urease activity. The effects of the given phytotoxic compounds, as well as the effects of soil exchangeable sorption according to the type of plant community, soil type and depth-where decreasing mineralization of phytotoxic substances with soil depth is expected-are to be observed in more depth in the future.

\section{Acknowledgements}

This research was supported by project QJ1320040 (Revitalization of ecosystem units with the use of ecological principles on the sites with strong anthropic influence in the past and extreme sites).

\section{References}

Amy, M., Cecchi, W. C., Koskinen, H. H., Cheng, H. 2004. Sorption-desorption of phenolic acids as affected by soil properties. Biol. Fertil. Soils. 39, 235-242.

Aragón, R., Sardans, J., Peñuelas, J. 2014. Soil enzymes associated with carbon and nitrogen cycling in invaded and native secondary forests of northwestern Argentina. Plant Soil. 384, 169-183.

Bardgett, R. D., Bowman, W. D., Kaufmann, R., Schmidt, S. K. 2005. A temporal approach to linking aboveground and belowground ecology. Trends Ecol. Evol. 20, 634-641.

Bergmark, C. L., Jackson, W. A., Volk, R. J., Blum, U. 1992. Differential inhibition by ferulic acid of nitrate and ammonium uptake in Zea mays L. Plant Physiol. 98, 639-645.

Błońska, E., Lasota, J. 2014. Biological and biochemical properties in evaluation of forest soil quality. Folia Forest. Polon. series A. 56, 23-29.

Booker, F. L., Blum, U., Fiscus, E. L. 1992. Shortterm effects of ferulic acid on ion uptake and water relations in cucumber seedlings. J. Exp. Bot. 43, 649-655.

Dilly, O., Nannipieri, P. 2001. Response of ATP content, respiration rate and enzyme activities in an arable and a forest soil to nutrient addition. Biol. Fertil. Soils. 34, 64-72.

Enowashu, E., Poll, CH., Lamersdorf, N., Kandeler, E. 2009. Microbial biomass and enzyme activities under reduced nitrogen deposition in a spruce forest soil. Appl. Soil Ecol. 43, 11-21.

Dong, Y. J., Wang, Z. L., Zhang, J. W., Liu, S., He, Z. L., \& He, M. R. 2015. Interaction effects of nitric oxide and salicylic acid in alleviating salt stress of Gossypium hirsutum L. J. Soil Sci. Plant Nutr. $15,561-573$. 
Geisseler, D., Horwath, W. R. 2008. Regulation of extracellular protease activity in soil in response to different sources and concentrations of nitrogen and carbon. Soil Biol. Biochem. 40, 3040-3048.

Harrison, K. A., Bol, R., Bardgett, R. D. 2008. Do plant species with different growth strategies vary in their ability to compete with soil microbes for chemical forms of nitrogen?. Soil Biol. Biochem. 40, 228-237.

IUSS Working Group WRB 2006. World Reference Base for Soil Resources 2006, 2nd ed. World Soil Resources Report 103, FAO, Rome, E.U., 103 p.

Kaiser, CH., Koranda, M., Kitzler, B., Fuchslueger, L., Schnecker, J., Schweiger, P., Rasche, F., Zechmeister-Boltenstern, S., Sessitsch, A., Richter, A. 2010. Belowground carbon allocation by trees drives seasonal patterns of extracellular enzyme activities by altering microbial community composition in a beech forest soil. New Phytol. 187, 843-858.

Kandeler, E., Gerber, H. 1988. Short-term assay of soil urease activity using colorimetric determination of ammonium. Biol. Fertil. Soils. 6, 68-72.

Kandeler, E., Luxhoi, J., Tscherko, D., Magid, J. 1999. Xylanase, invertase and protease at the soil-litter interface of a loamy sand. Soil Biol. Biochem. 31, 1171-1179.

Kang, H., Kang S., Lee, D. 2009. Variations of soil enzyme activities in a temperate forest soil. Ecol. Res. 24, 1137-1143.

Kassambra, A., Mundt, F. 2017. Extract and Visualize the Results of Multivariate Data Analyses. Package "factoextra", version 1.0.4. https:// cran.r-project.org/web/packages/factoextra/factoextra.pdf.
Kučera, A., Holik, L., Marosz, K., Martinik, A., Vavricek, D. 2013. Changes in forms of available nitrogen and respiration in soil of beech forest as a reaction to a deforestation resulting from wind storm. Acta Univ. agric. Silvic. Mendel. Brunensis. $1,107-113$.

Ladd, J. N. 1972. Properties of proteolytic enzymes extracted from soil. Soil Biol. Biochem. 4, 227237.

Lyu, S. W., Blum, U., Gerig, T. M., O’Brien, T. E. 1990. Effects of mixtures of phenolic acids on phosphorus uptake by cucumber seedlings. J. Chem. Ecol. 6, 2559-2567.

Mauch, F., Mauch-Mani, B., Gaille, C., Kull, B., Haas, D. Reimmann, C. 2001. Manipulation of salicylate content in Arabidopsis thaliana by the expression of an engineered bacterial salicylate synthase. Plant J. 25, 67-77.

Moe, L.A. 2013. Amino acids in the rhizosphere: From plants to microbes. Am. J. Bot. 100, 1692 -1705 .

Muscolo, A., Sidari, M. 2006. Seasonal fluctuations in soil phenolics of a coniferous forest: effects on seed germination of different coniferous species. Plant Soil. 284, 305-318.

Ojeda-Barrios, D. L., Sánchez-Chávez, E., Sida-Arreola, J. P., Valdez-Cepeda, R., Balandran-Valladares, M. 2016. The impact of foliar nickel fertilization on urease activity in pecan trees. J. Soil Sci. Plant Nutr. 16, 237-247.

Popova, L., Pancheva, T., Uzunova, A. 1997. Salicylic acid: Properties, biosynthesis and physiological role. Bulg. J. Plant Physiol. 23, 85-93.

Schettel, N. L., Balke, N. E. 1983. Plant growth response to several allelopathic chemicals. Weed Sci. 31, 293-298. 
Tharayil, N., Alpert, P., Bhowmik, P. C., Gerard, P. 2013. Phenolic inputs by invasive species could impart seasonal variations in nitrogen pools in the introduced soils: a case study with Polygonum cuspidatum. Soil Biol. Biochem. 57, 858-867.

Vetanovetz, R. P., Peterson, J.C. 1992. Effect of carbon source and nitrogen on urease activity in a Sphagnum peat medium. Commun. Soil Sci. Plant Anal. 23, 379-388.

Vranova, V., Formánek, P., Rejšek, K., Pavelka, M. 2009. Impact of land-use change on proteolytic activity of mountain meadows. Soil Water Res. 4, 122-125.
Vranova, V., Rejšek, K., Formánek, P. 2013. Proteolytic activity in soil: A review. Appl. Soil Ecol. 70, 23-32.

Weintraub, M. N., Schimel, P. 2005. Seasonal protein dynamics in Alaskan arctic tundra soils. Soil Biol. Biochem. 37, 1469-1475. 